\title{
BIOMECHANICAL ACCESS METHOD FOR ANALYZING ISOMETRICITY IN RECONSTRUCTING THE MEDIAL PATELLOFEMORAL LIGAMENT
}

David Sadigursky', Riccardo Gomes Gobbi², César Augusto Martins Pereira ${ }^{3}$, José Ricardo Pécora ${ }^{4}$, Gilberto Luis Camanho 5

\section{ABSTRACT}

Objective: To present a biomechanical device for evaluating medial patellofemoral ligament (MPFL) reconstruction and its isometricity. Methods: An accessible biomechanical method that allowed application of physiological and non-physiological forces to the knee using a mechanical arm and application of weights and counterweights was developed, so as to enable many different evaluations and have a very accurate measurement system for distances between different structures, for analysis on experiments. This article describes the assembly of this system, and suggests some practical applications. Six cadaver knees were studied. The knees were prepared in a testing machine developed at the Biomechanics Laboratory of IOT-HCFMUSP, which allowed dynamic evaluation of patellar behavior, with quantification of patellar lateralization be- tween $0^{\circ}$ and $120^{\circ}$. The differences between the distances found with and without load applied to the patella were grouped according to the graft fixation angle $\left(0^{\circ}, 30^{\circ}, 60^{\circ}\right.$ or $90^{\circ}$ ) and knee position (intact, damaged or reconstructed). Results: There was a tendency for smaller lateral displacement to occur at fixation angles greater than 30 degrees of flexion, especially between the angles of $45^{\circ}$ and $60^{\circ}$ degrees of flexion, after the reconstruction. For the other angles, there was no statistical significance. Conclusion: The method developed is a useful tool for studies on the patellofemoral joint and the MPFL, and has a very accurate measurement system for distances between different structures. It can be used in institutions with fewer resources available.

Keywords - Knee/surgery; Joint Instability; Biomechanics; Patellar Ligament

\section{INTRODUCTION}

The medial patellofemoral ligament (MPFL) has been documented as the greatest restrictor of lateral translation of the patella ${ }^{(1-3)}$. In most patients, the MPFL is ruptured during acute dislocation of the patella $a^{(4,5)}$. For this reason, a large number of surgical techniques for treating patellar instability have been described ${ }^{(6)}$.

Starting in the 1990s, a growing number of studies dealing specifically with reconstruction of the MPFL appeared in the literature ${ }^{(7-16)}$. Reconstruction of this ligament has been shown to be an excellent alterna- tive for restoring both the anatomy and the function of the medial patellofemoral joint. The grafts used for reconstructing this ligament have ranged from synthetic grafts to grafts from the semitendinosus, gracilis and quadriceps tendons and the patellar ligament $^{(2,9,13,16-23)}$.

Since the start of the $21^{\text {st }}$ century, biomechanical studies on cadavers have been developed using simulators constructed for analysis on the patellofemoral joint ${ }^{(7,17,21,24-33)}$. These studies can be divided into anatomical and biomechanical. Anatomical studies have

1 - MSc from the Institute of Orthopedics and Traumatology, Hospital das Clínicas, School of Medicine, University of São Paulo, São Paulo, SP, Brazil.

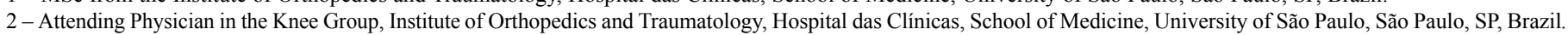

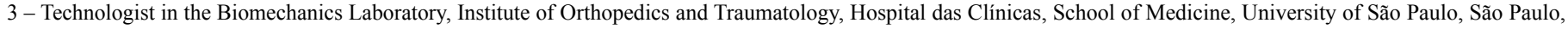
SP, Brazil.

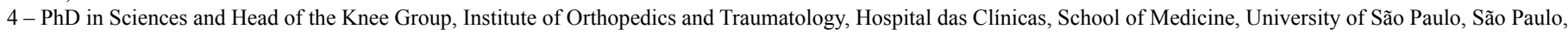
SP, Brazil.

5 - Titular Professor and Head of the Department of Orthopedics and Traumatology, School of Medicine, University of São Paulo, São Paulo, SP, Brazil.

Work performed at the Institute of Orthopedics and Traumatology, Hospital das Clínicas, School of Medicine, University of São Paulo.

Correspondence: Rua Colmar Americano da Costa 121, Pituba, 41815-090 Salvador, BA. E-mail: davidsad@gmail.com

Work received for publication: October 26, 2011; accepted for publication: November 29, 2011.

The authors declare that there was no conflict of interest in conducting this work 
been better accepted in the literature, given that they directly assess the reality of structures that make up the human body. On the other hand, biomechanical studies have been much criticized and need to be examined with care, given that they present controlled situations with very limited reproducibility, relating to a mechanical demand that might occur in real life. The most evident example of this is the lack of dynamic muscle action for stabilization of a joint.

Several models in biomechanical studies have attempted to address this failing, through simulating muscle loading by means of fixed weights or weights transferred to muscle structures ${ }^{(27,34)}$. The problem is that many of these models are complex and poorly reproducible, either because of their cost or because of the need for very specialized instrumentation.

In this paper, we present a device developed by the Biomechanics Laboratory of the Institute of Orthopedics and Traumatology, Hospital das Clínicas, School of Medicine of the University of São Paulo (IOT-HC-FMUSP), which makes it possible to simulate biomechanical situations close to reality on the knees of cadavers, through using weights and counterweights with accuracy calculations based on previously published values, and which also enables measurement of the distances between anatomical structures through a precise method based on analysis of photographs (photogrammetry) (35). We believe that this method is very useful in biomechanical analyses, since it is reproducible and not does have high costs.

\section{MATERIALS AND METHODS}

\section{Obtaining and preparing the anatomical specimens}

The study was conducted using six anatomical knee specimens taken from recent cadavers. The cadaver specimens came from the Death Verification Service of the city of São Paulo, after obtaining approval from the Scientific Committee of the Institute of Orthopedics and Traumatology (IOT), University of São Paulo, and from the Ethics Committee for Analysis of Research Projects (CAPPesq) of Hospital das Clínicas, School of Medicine of the University of São Paulo (FMUSP).

\section{Group formation}

The MPFL was reconstructed by means of resec- tion of the middle third of the patellar ligament, in accordance with the surgical technique described by Camanho et $a l^{(16)}$ and it was fixed at angles of 0,30 , 60 and 90 degrees. All the trials were sequenced, in such a way that the same knee was subjected firstly to trials with its tendon and ligament structures intact, and then with the MPFL injured and lastly with the ligament reconstructed and fixed with the knee positioned at the angles of $0,30,60$ and 90 degrees of flexion.

\section{Reconstruction using the patellar ligament}

The surgical procedure was performed using the patellar ligament as an autogenous graft, starting with an incision proximally to the upper margin of the patella, centered between the medial margin of the patella and medial epicondyle, and going towards the medial margin of the anterior tuberosity of the tibia (Figure 1).

\section{Test method}

All the specimens that had previously been selected for the study were evaluated mechanically in three distinct situations: with the MPFL intact, injured and reconstructed. In each situation, the knee was subjected to mechanical tests, divided into two test sequences. In the first sequence, the tests were repeated three times with the knee subjected to flexionextension movement, from 120 to $0^{\circ}$, without any load applied laterally to the patella. In the second sequence, another three tests were repeated with the

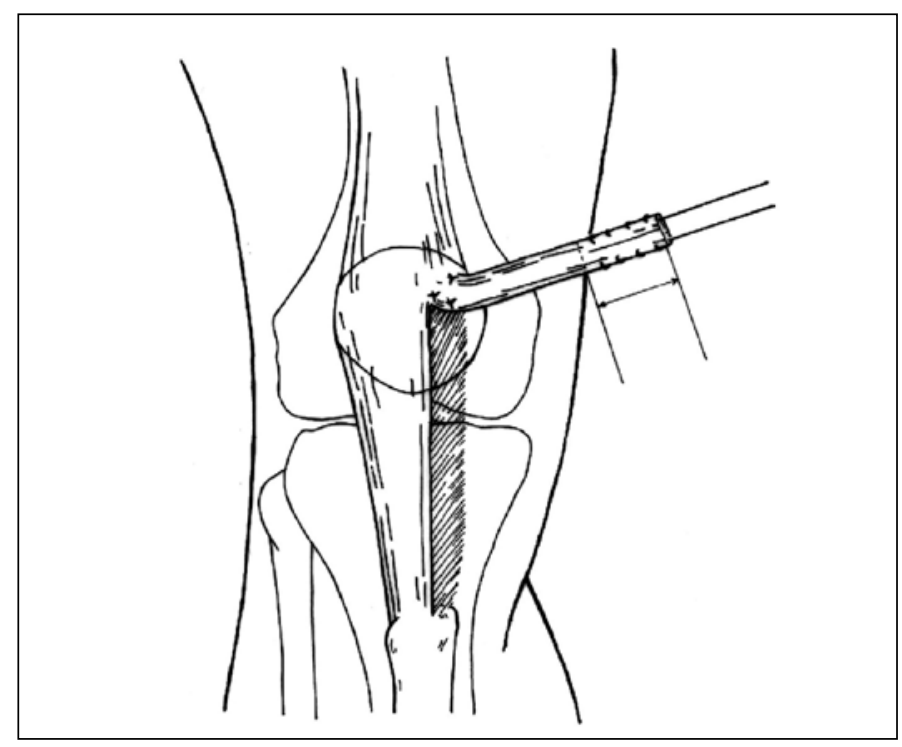

Figure 1 - Resection of the middle third of the patellar ligament going towards the medial edge of the patella, between the middle and proximal thirds (reproduced with permission from Camanho et al) ${ }^{(16)}$. 
knee subjected to the same flexion-extension movement, but with the patella lateralized by means of a static load of $33.3 \mathrm{~N}(3.39 \mathrm{~kg})$.

A mechanical device with the function of carrying out the abovementioned tests was developed at the Biomechanics Laboratory of IOT-HC-FMUSP. This device was coupled to a $\mathrm{Kratos}^{\circledR} \mathrm{K} 5002$ universal mechanical test machine, equipped with a $5 \mathrm{tf}$ load cell (Figure 2). All the information coming from the tests was controlled by a data acquisition system (Lynx Technology, model ADS-2000). Figure 3 illustrates a right knee positioned in the mechanical device developed.

With the objective of standardizing the force applied laterally to the patella, with the purpose of provoking subluxation of the patella, a force of $1 \mathrm{kgf}$ was exerted on the graft during its fixation at the four different knee flexion angles. A load cell of $20 \mathrm{kgf}$ that had been developed at the Biomechanics Laboratory (Figure 4) was coupled laterally in the femoral tunnel that had been created for the graft to pass through, with the aim of measuring the force used at the time of its fixation, and this standardized force was maintained for all the tests.

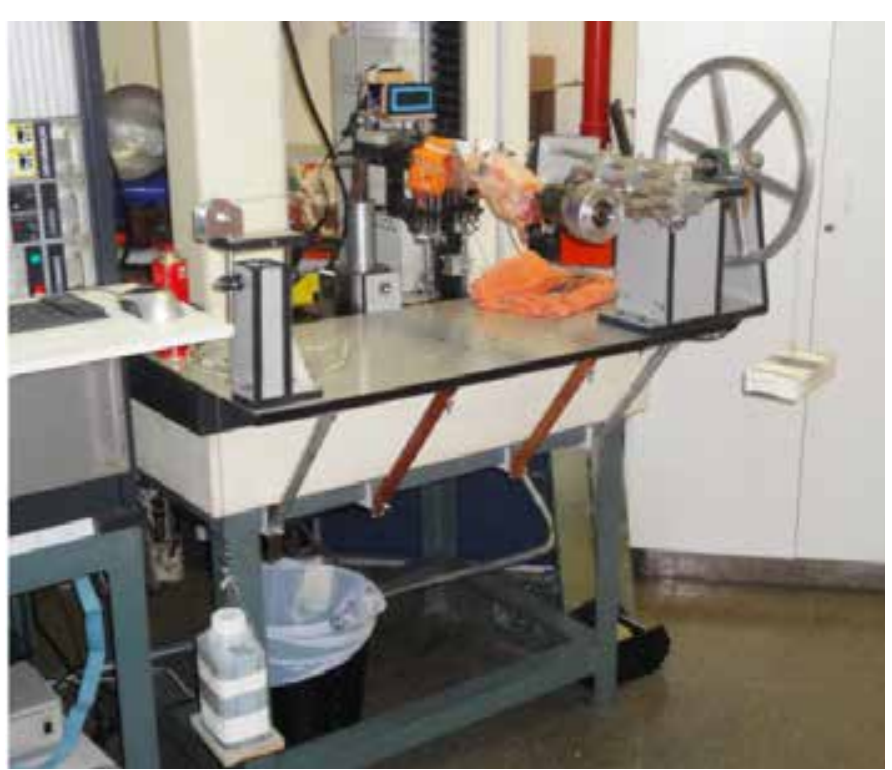

Figure 3 - Right knee fixed to the mechanical device, showing the weight coupled to the pulley (right) and the weight used to lateralize the patella (left).

In detail, the Ethibond ${ }^{\circledR}$ wires were tied to the upper beam of the load cell.

With the aim of monitoring the displacement of the patella in relation to a reference point on the femur, a three-dimensional photogrammetry system was developed at the Biomechanics Laboratory, based on

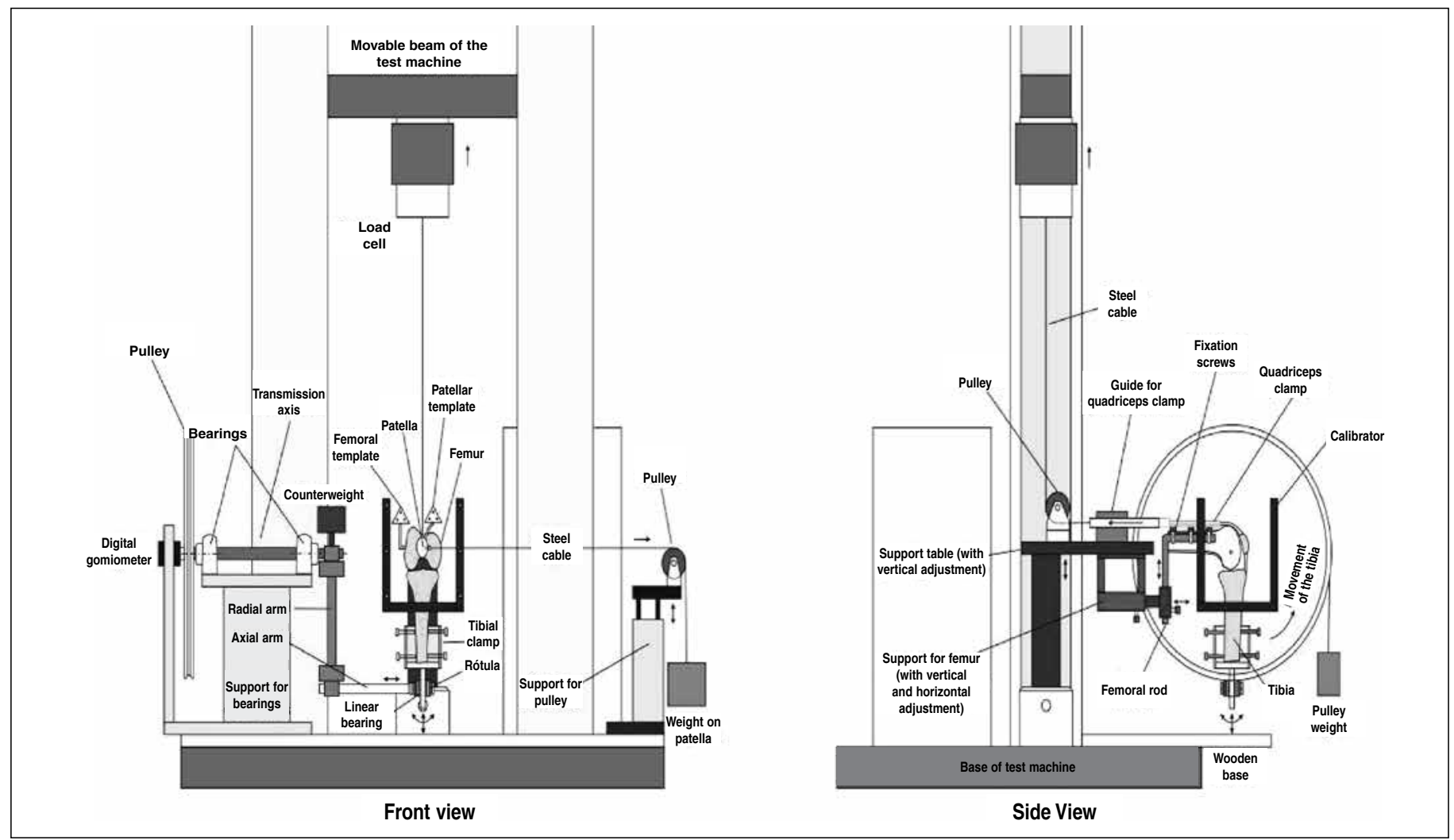

Figure 2 - Schematic representation of the left knee positioned in the mechanical device coupled to the universal mechanical test device. Front and side views of the components of the device. 


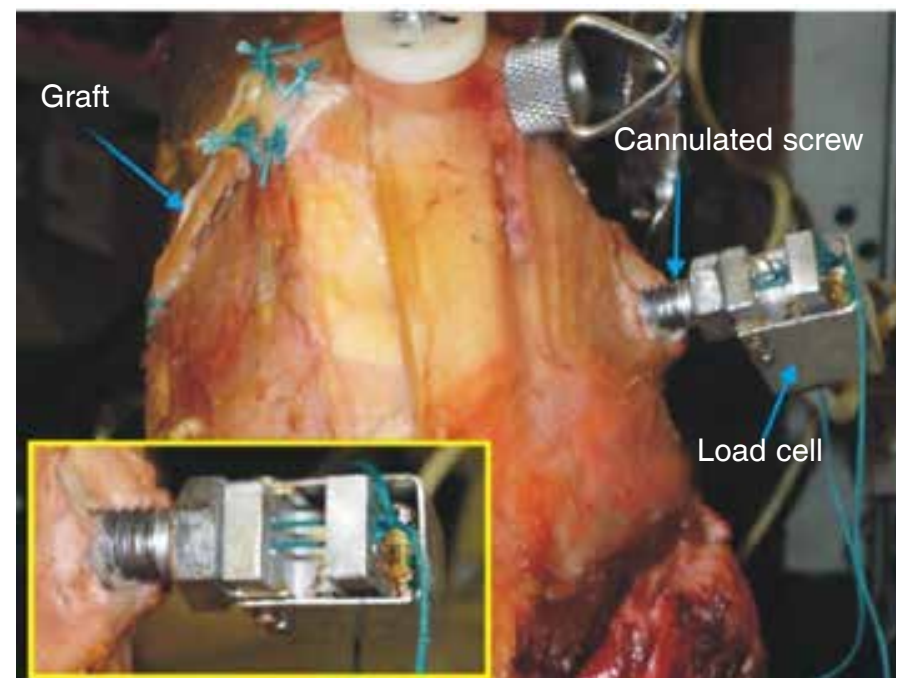

Figure 4 - Graft fixation system with cannulated screw and load cell. In detail, the Ethibond ${ }^{\circledR}$ wires tied to the upper beam of the load cell.

the model developed by Abdel-Aziz and Karara( ${ }^{(35)}$, which measured the positioning of the patella during the tests, with the knee positioned at flexion-extension of $120^{\circ}, 105^{\circ}, 90^{\circ}, 75^{\circ}, 60^{\circ}, 45^{\circ}, 30^{\circ}, 15^{\circ}$ and $0^{\circ}$.

This system comprised the following: another computer program in the Delphi ${ }^{\circledR}$ language, two digital photographic cameras, a three-dimensional calibrator and two templates fixed to the femur and patella.

The measurements on the three-dimensional coordinates of the 12 markers of the calibrator were made in the Dimensional Metrology Laboratory of the Institute of Industrial Studies and Research (IPEI), University Center of the School of Industrial Engineering (FEI), using a three-dimensional coordinate measurement machine (Mitutoyo ${ }^{\circledR}$, model QM-353/189-314 BR) with a measurement uncertainty of $0.012 \mathrm{~mm}$.

The template was composed of a small triangular plate containing three points similar to the markers of the calibrator, distributed at the vertices of an equilateral triangle, equidistant at around $21.3 \mathrm{~mm}$ from each other. Two templates were used: their measurements were made by the same laboratory that made the measurements on the calibrator. One template was fixed using two screws in the medial region of the patella and the other was placed in the posterior region of the femur (close to the capsule) by means of two cortical screws and an osteosynthesis plate molded for correct positioning of the template (Figure 5).

A computer program was developed in the Delphi ${ }^{\circledR}$ language with the functions of controlling (via ADS 2000) the up and down movements of the movable beam of the test machine and the action of the remote

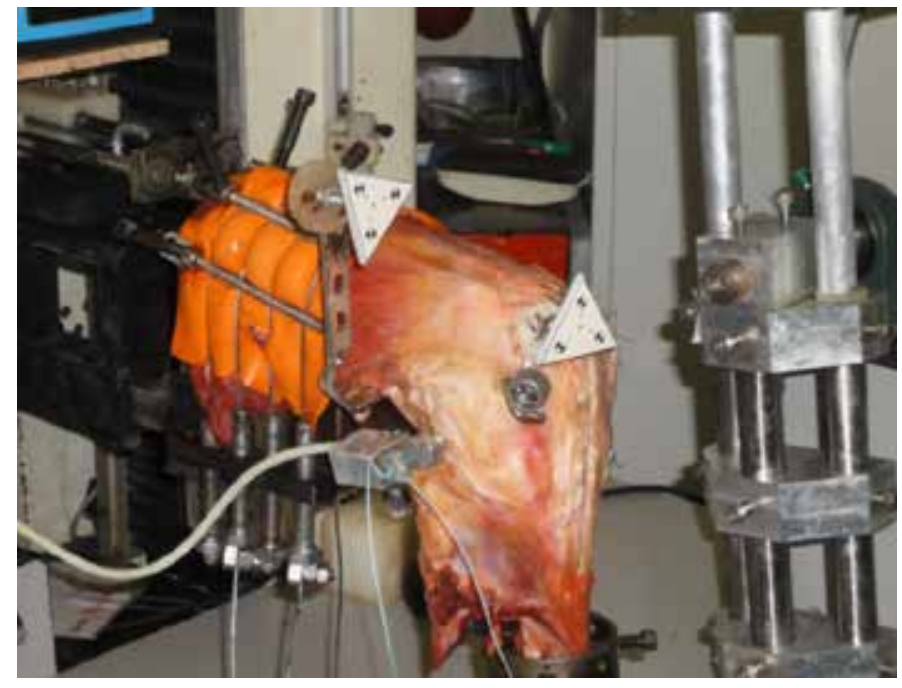

Figure 5 - Triangular templates used in the three-dimensional measurement process.

control, and recording the angle of knee flexionextension by means of digital goniometry and the force coming from the load cell.

The program correlated the two-dimensional coordinates of the markers present in the two templates, which were located on the pair of photographs obtained during the measurement process, with the twodimensional coordinates of the 12 markers located on the two photographs that were obtained during the calibration process (Figure 5), by means of direct linear transformation (DLT), as described by AbdelAziz and Karara ${ }^{(35)}$. The center of each marker was located automatically by the program, which generated a report with the special coordinates of the six markers distributed on the two templates.

Following this, measurements of the lateromedial deviation of the patella marker under the conditions of load application and without lateral loads were calculated.

The distances with and without load applied to the patella were grouped according to the angle of graft fixation $\left(0^{\circ}, 30^{\circ}, 60^{\circ}\right.$ and $\left.90^{\circ}\right)$ and situation of the knee (intact, injured or reconstructed). The results were tabulated from the means of the three repetitions.

\section{RESULTS}

Table 1 shows the descriptive statistics on the differences between the distances with and without load applied to the patella, according to the angle of knee flexion $\left(0^{\circ}, 15^{\circ}, 30^{\circ}, 45^{\circ}, 60^{\circ}, 75^{\circ}, 90^{\circ}, 105^{\circ}\right.$ and $120^{\circ}$ ) and the situation of the knee (intact, injured or 
reconstructed). These results were obtained from the means of the three measurements made on each knee for each situation and are presented in Figures 6 and 7.

Statistically significant differences were found in relation to lateralization of the patella, both between the angles of graft reconstruction $(p<0.001)$

Table 1 - Description of the lateralization of the patella according to the graft reconstruction angle and the knee flexion angle.

\begin{tabular}{|c|c|c|c|c|c|c|c|}
\hline $\begin{array}{c}\text { Flexion- } \\
\text { extension }\end{array}$ & MPFL conditions & $n$ & mean & SD & median & Minimum & Maximum \\
\hline \multirow{6}{*}{$0^{\circ}$} & Intact & 6 & 1.75 & 0.23 & 1.70 & 1.50 & 2.10 \\
\hline & Reconstructed $0^{\circ}$ & 6 & 8.13 & 0.10 & 8.10 & 8.00 & 8.30 \\
\hline & Reconstructed $45^{\circ}$ & 6 & 7.40 & 0.17 & 7.35 & 7.20 & 7.60 \\
\hline & Reconstructed $60^{\circ}$ & 6 & 5.67 & 0.15 & 5.60 & 5.50 & 5.90 \\
\hline & Reconstructed $90^{\circ}$ & 6 & 6.65 & 0.14 & 6.65 & 6.50 & 6.80 \\
\hline & Injured & 6 & 9.50 & 0.13 & 9.50 & 9.20 & 9.60 \\
\hline \multirow{6}{*}{$15^{\circ}$} & Intact & 6 & 1.58 & 0.19 & 1.55 & 1.40 & 1.90 \\
\hline & Reconstructed $0^{\circ}$ & 6 & 7.97 & 0.10 & 8.00 & 7.80 & 8.10 \\
\hline & Reconstructed $45^{\circ}$ & 6 & 7.18 & 0.15 & 7.15 & 7.00 & 7.40 \\
\hline & Reconstructed $60^{\circ}$ & 6 & 5.53 & 0.16 & 5.55 & 5.30 & 5.70 \\
\hline & Reconstructed $90^{\circ}$ & 6 & 6.37 & 0.14 & 6.35 & 6.20 & 6.60 \\
\hline & Injured & 6 & 9.32 & 0.13 & 9.40 & 9.10 & 9.40 \\
\hline \multirow{6}{*}{$30^{\circ}$} & Intact & 6 & 1.47 & 0.16 & 1.45 & 1.30 & 1.70 \\
\hline & Reconstructed $0^{\circ}$ & 6 & 7.87 & 0.10 & 7.90 & 7.70 & 8.00 \\
\hline & Reconstructed $45^{\circ}$ & 6 & 7.08 & 0.15 & 7.05 & 6.90 & 7.30 \\
\hline & Reconstructed $60^{\circ}$ & 6 & 5.41 & 0.17 & 5.40 & 5.20 & 5.60 \\
\hline & Reconstructed $90^{\circ}$ & 6 & 6.20 & 0.09 & 6.20 & 6.10 & 6.30 \\
\hline & Injured & 6 & 9.22 & 0.12 & 9.25 & 9.00 & 9.30 \\
\hline \multirow{6}{*}{$45^{\circ}$} & Intact & 6 & 1.30 & 0.14 & 1.30 & 1.10 & 1.50 \\
\hline & Reconstructed $0^{\circ}$ & 6 & 7.77 & 0.10 & 7.80 & 7.60 & 7.90 \\
\hline & Reconstructed $45^{\circ}$ & 6 & 6.98 & 0.15 & 6.95 & 6.80 & 7.20 \\
\hline & Reconstructed $60^{\circ}$ & 6 & 5.32 & 0.12 & 5.30 & 5.20 & 5.50 \\
\hline & Reconstructed $90^{\circ}$ & 6 & 6.10 & 0.09 & 6.10 & 6.00 & 6.20 \\
\hline & Injured & 6 & 9.12 & 0.12 & 9.15 & 8.90 & 9.20 \\
\hline \multirow{6}{*}{$60^{\circ}$} & Intact & 6 & 1.20 & 0.14 & 1.20 & 1.00 & 1.40 \\
\hline & Reconstructed $0^{\circ}$ & 6 & 7.67 & 0.10 & 7.70 & 7.50 & 7.80 \\
\hline & Reconstructed $45^{\circ}$ & 6 & 6.88 & 0.15 & 6.85 & 6.70 & 7.10 \\
\hline & Reconstructed $60^{\circ}$ & 6 & 5.22 & 0.12 & 5.20 & 5.10 & 5.40 \\
\hline & Reconstructed $90^{\circ}$ & 6 & 6.00 & 0.09 & 6.00 & 5.90 & 6.10 \\
\hline & Injured & 6 & 9.02 & 0.12 & 9.05 & 8.80 & 9.10 \\
\hline \multirow{6}{*}{$75^{\circ}$} & Intact & 6 & 1.10 & 0.14 & 1.10 & 0.90 & 1.30 \\
\hline & Reconstructed $0^{\circ}$ & 6 & 7.57 & 0.10 & 7.60 & 7.40 & 7.70 \\
\hline & Reconstructed $45^{\circ}$ & 6 & 6.78 & 0.15 & 6.75 & 6.60 & 7.00 \\
\hline & Reconstructed $60^{\circ}$ & 6 & 5.12 & 0.12 & 5.10 & 5.00 & 5.30 \\
\hline & Reconstructed $90^{\circ}$ & 6 & 5.90 & 0.09 & 5.90 & 5.80 & 6.00 \\
\hline & Injured & 6 & 8.92 & 0.12 & 8.95 & 8.70 & 9.00 \\
\hline \multirow{6}{*}{$90^{\circ}$} & Intact & 6 & 1.00 & 0.14 & 1.00 & 0.80 & 1.20 \\
\hline & Reconstructed $0^{\circ}$ & 6 & 7.47 & 0.10 & 7.50 & 7.30 & 7.60 \\
\hline & Reconstructed $45^{\circ}$ & 6 & 6.68 & 0.15 & 6.65 & 6.50 & 6.90 \\
\hline & Reconstructed $60^{\circ}$ & 6 & 5.02 & 0.12 & 5.00 & 4.90 & 5.20 \\
\hline & Reconstructed $90^{\circ}$ & 6 & 5.80 & 0.09 & 5.80 & 5.70 & 5.90 \\
\hline & Injured & 6 & 8.82 & 0.12 & 8.85 & 8.60 & 8.90 \\
\hline \multirow{6}{*}{$105^{\circ}$} & Intact & 6 & 0.90 & 0.14 & 0.90 & 0.70 & 1.10 \\
\hline & Reconstructed $0^{\circ}$ & 6 & 7.36 & 0.10 & 7.40 & 7.20 & 7.50 \\
\hline & Reconstructed $45^{\circ}$ & 6 & 6.62 & 0.15 & 6.65 & 6.40 & 6.80 \\
\hline & Reconstructed $60^{\circ}$ & 6 & 4.92 & 0.12 & 4.90 & 4.80 & 5.10 \\
\hline & Reconstructed $90^{\circ}$ & 6 & 5.70 & 0.09 & 5.70 & 5.60 & 5.80 \\
\hline & Injured & 6 & 8.72 & 0.12 & 8.75 & 8.50 & 8.80 \\
\hline \multirow{6}{*}{$120^{\circ}$} & Intact & 6 & 0.80 & 0.14 & 0.80 & 0.60 & 1.00 \\
\hline & Reconstructed $0^{\circ}$ & 6 & 7.27 & 0.10 & 7.30 & 7.10 & 7.40 \\
\hline & Reconstructed $45^{\circ}$ & 6 & 6.55 & 0.16 & 6.60 & 6.30 & 6.70 \\
\hline & Reconstructed $60^{\circ}$ & 6 & 4.82 & 0.12 & 4.80 & 4.70 & 5.00 \\
\hline & Reconstructed $90^{\circ}$ & 6 & 5.60 & 0.09 & 5.60 & 5.50 & 5.70 \\
\hline & Injured & 6 & 8.62 & 0.12 & 8.65 & 8.40 & 8.70 \\
\hline
\end{tabular}

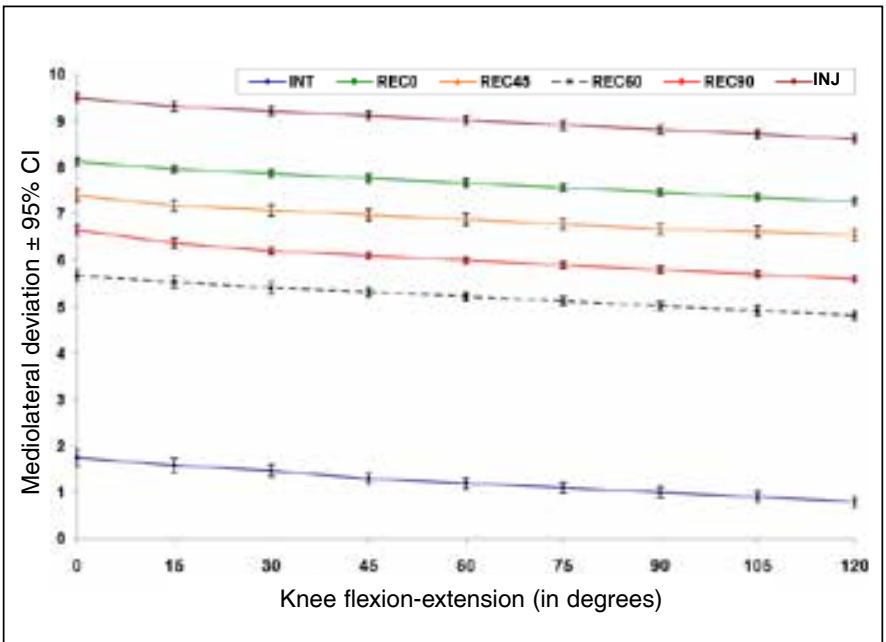

Figure 6 - Mediolateral deviation of the patella \pm standard error, according to the graft reconstruction angle and the knee flexion angle.

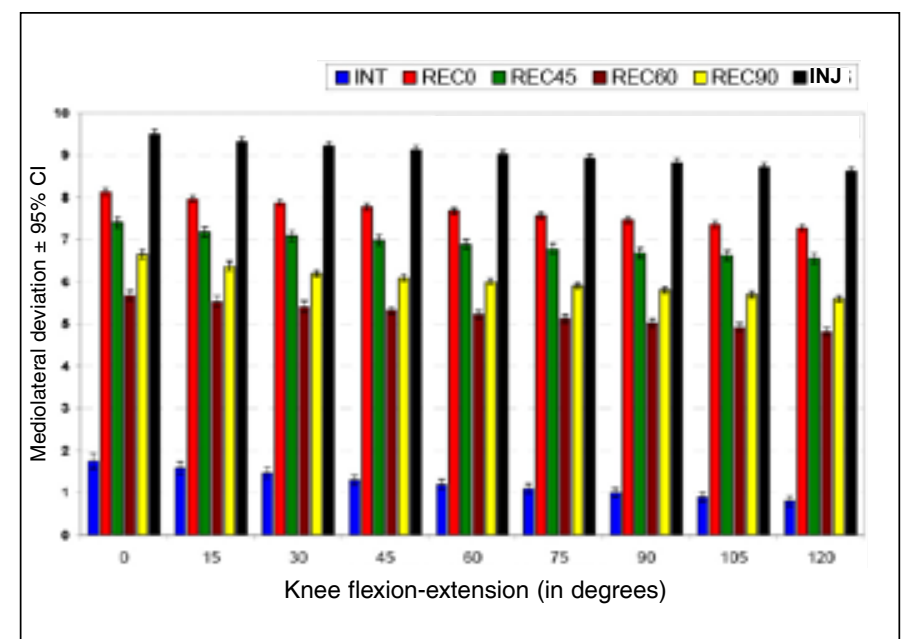

Figure 7 - Mediolateral deviation of the patella \pm standard error, according to the graft reconstruction angle and the knee flexion angle.

and between the angles of knee flexion-extension ( $p$ $<0.001)$. However, no alterations in behavior were observed with regard to the mean deviation of lateralization of the patella between the MPFL conditions across the flexion-extension parameters used (interaction of reconstruction * flexion-extension; $p=0.997$ ) (Figures 6 and 7).

With the aim of investigating the reconstruction graft angles for which there were statistically significant differences, Tukey multiple comparisons were conducted $^{(36)}$ (Table 2).

For all the flexion-extension angles, greater lateralization was observed in the reconstruction of the injured knee, in comparison with the other situations; and the least lateralization was observed at the reconstruction of $60^{\circ}$, independent of the flexion-extension angle. 
Table 2 - Multiple comparisons of the standard deviations for lateralization of the patella with the graft reconstruction angles.

\begin{tabular}{c|c|c|c|c}
\hline \multicolumn{2}{c|}{ Comparison } & $\begin{array}{c}\text { Estimated } \\
\text { mean } \\
\text { difference }\end{array}$ & $\begin{array}{c}\text { Standard } \\
\text { error }\end{array}$ & p value \\
\hline Intact & Lesado & -7.787 & 0.022 & $<0.001$ \\
\hline Intact & Reconstructed $0^{\circ}$ & -6.441 & 0.022 & $<0.001$ \\
\hline Intact & Reconstructed $45^{\circ}$ & -5.674 & 0.022 & $<0.001$ \\
\hline Intact & Reconstructed $60^{\circ}$ & -3.991 & 0.022 & $<0.001$ \\
\hline Intact & Reconstructed $90^{\circ}$ & -4.802 & 0.022 & $<0.001$ \\
\hline Injured & Reconstructed $0^{\circ}$ & 1.346 & 0.022 & $<0.001$ \\
\hline Injured & Reconstructed $45^{\circ}$ & 2.113 & 0.022 & $<0.001$ \\
\hline Injured & Reconstructed $60^{\circ}$ & 3.796 & 0.022 & $<0.001$ \\
\hline Injured & Reconstructed $90^{\circ}$ & 2.985 & 0.022 & $<0.001$ \\
\hline Reconstructed $0^{\circ}$ & Reconstructed $45^{\circ}$ & 0.767 & 0.022 & $<0.001$ \\
\hline Reconstructed $0^{\circ}$ & Reconstructed $60^{\circ}$ & 2.450 & 0.022 & $<0.001$ \\
\hline Reconstructed $0^{\circ}$ & Reconstructed $90^{\circ}$ & 1.639 & 0.022 & $<0.001$ \\
\hline Reconstructed $45^{\circ}$ & Reconstructed $60^{\circ}$ & 1.683 & 0.022 & $<0.001$ \\
\hline Reconstructed $45^{\circ}$ & Reconstructed $90^{\circ}$ & 0.872 & 0.022 & $<0.001$ \\
\hline Reconstructed $60^{\circ}$ & Reconstructed $90^{\circ}$ & -0.811 & 0.022 & $<0.001$ \\
\hline
\end{tabular}

\section{DISCUSSION}

The methodology used in the present study was based on the study of Ostermeier et $a l^{(34)}$. Similarly, their study used a device that would allow knee extension movement through traction of the quadriceps with resistance to the movement, with lateral loading applied to the patella and measurement of the translation of the patella. However, the mechanical conception of the device and the method of measuring the displacement of the patella were different and adapted such that the studies could be conducted with the resources available.

Patellofemoral instability may result from anatomical factors that contribute towards greater lateralization of the patella. However, studies like those of Ahmad et $a l^{(37)}$, Steiner et $a l^{(22)}$ and Watanabe et $a l^{(38)}$ demonstrate that reconstruction of the MPFL alone is effective even in cases with associated predisposing factors. Moreover, the same situation was reached in all the tests, and the force that caused the dislocation of the patella could be standardized in all the test sequences. The choice of force applied laterally to the patella was in accordance with the known data on forces resulting in patellar displacement, from previous studies $^{(1,24,27)}$. Thus, the factors predisposing towards instability (patellar dysplasia, trochlear dysplasia and increased anterior tuberosity-trochlear groove distance), which may be associated in anatomical speci- mens, can be leveled in comparative tests like the present one, given that all the specimens were tested under the same test conditions ${ }^{(39)}$.

It has been suggested that this laterally directed force might be less than the force that causes complete rupture of the MPFL $(200 \mathrm{~N})^{(18,26)}$, but would result in significant lateral displacement of the patella without irreversible effects on the medial soft tissue contributing towards its restriction ${ }^{(27)}$. The force applied laterally in the present study was fixed to the lateral margin of the patella in order to minimize the influence of patellar tilt, in accordance with the study by Sandmeier et $a l^{(24)}$.

In all the tests, we applied a load of $1 \mathrm{~kg}$, based on the biomechanical study of Beck et $a l^{(30)}$, thereby demonstrating that a maximum traction of between $2 \mathrm{~N}$ and $10 \mathrm{~N}$ would be sufficient and adequate for stabilizing the reconstruction of the MPFL, and would not cause any increase in medial contact pressure of the patellofemoral joint.

Ostermeier et $a l^{(34)}$ used an extension moment of 31 N.m that represented the physiological extension moment measured in healthy individuals undergoing isokinetic knee extension tests. However, if this is extrapolated to individuals undergoing reconstruction of the MPFL, application of this torque value during the initial recovery phase may be harmful. For this reason, a torque value corresponding to one third of the value of 31 N.m was applied for the flexion moment, as discussed by Beck et $a l^{(30)}$. With the aim of maintaining the same proportions between the flexion torque and the load applied to the patella, the value of one third of $100 \mathrm{~N}$ recommended by Ostermeier et $a l^{(40)}$ was used to promote lateralization of the patella.

In the present study, we evaluated the reconstruction of the MPFL with regard to the best knee flexion angle for graft fixation, along with the mediolateral path of the patella during knee flexion-extension. Through this, it could be affirmed that greater lateralization of the patella occurred at the first angles of knee flexion. This could, under conditions of injury to this ligament, promote dislocation of the patella in relation to the femoral trochlea. From the graphs and values presented in the statistical analysis, it could be seen that reconstruction of the MPFL fixed at angles less than 30 degrees of knee flexion promoted greater lateralization of the patella, thus coming close to the condition of an injured ligament. During knee flexion- 
-extension, it could be seen, like in previous biomechanical studies ${ }^{(29)}$, that the patella tended to dislocate at the first angles of flexion. This can be explained by the absence of bone structures acting as stabilizers at these angles, such that the MPFL was performing the function of primary restrictor against dislocation of the patella $^{(41)}$. Thus, centralization of the patella in relation to the femur can be maintained at angles of 45 to 60 degrees, which favors correct fixation of the graft. At angles less than 30 degrees, the MPFL is under tension and without adequate bone protection against lateral displacement of the patella ${ }^{(29)}$. Consequently, when the graft of the MPFL is fixed at these angles, excessive tensioning of the graft may occur, due to the absence of adequate medial parameters for determining its position, thus promoting increased pressure from the medial facet of the patella ${ }^{(39)}$. At angles greater than 70 degrees, the MPFL is found to be slack, and tensioning of the graft above this angle is capable of inducing excessive medialization of the patella.

The force exerted by the hamstrings during knee extension promotes additional stabilization of the patellofemoral joint, thereby controlling tibial rotation ${ }^{(42)}$. In our study, we standardized the force by fixing the tibia and making use of a counterweight to the extensor force of the quadriceps. Absence of weight-bearing, which has a stabilizing effect during the movement of the patella, may lead to systematic bias ${ }^{(34)}$.

The present study serves as a further aid towards decision-making during surgery for correction of patellofemoral instability, with regard to reconstruction of the MPFL. The cost of constructing the test apparatus is low in comparison with the methods found in the literature ${ }^{(27)}$ : a total of 11,000 dollars for the system. It can be used in less developed countries that lack the resources to purchase high-cost apparatus.

Examples of uses for this system include biomechanical studies that involve measurements of patella subluxation, with analysis on reconstruction of the MPFL using different grafts; studies on the isometry of different anatomical studies; studies on translation between the tibia and femur following different techniques for ligament reconstruction; and thus likewise comparing the different types of graft available. Through small adjustments to the device, these experiments are fully feasible.

\section{CONCLUSION}

This method developed in the biomechanics laboratory will be a useful tool for evaluating isometricity of the MPFL and of the patella and thus reconstruction of the MPFL.

\section{REFERENCES}

1. Conlan T, Garth WP Jr, Lemons JE. Evaluation of the medial soft-tissue restraints of the extensor mechanism of the knee. J Bone Joint Surg Am. 1993;75(5):682-93.

2. Desio SM, Burks RT, Bachus KN. Soft tissue restraints to lateral patellar translation in the human knee. Am J Sports Med. 1998;26(1):59-65.

3. Steensen RN, Dopirak RM, Maurus PB. A simple technique for reconstruction of the medial patellofemoral ligament using a quadriceps tendon graft. Arthroscopy. 2005;21(3):365-70.

4. Sallay PI, Poggi J, Speer KP, Garrett WE. Acute dislocation of the patella. A correlative pathoanatomic study. Am J Sports Med. 1996;24(1):52-60.

5. Sanders TG, Morrison WB, Singleton BA, Miller MD, Cornum KG. Medial patellofemoral ligament injury following acute transient dislocation of the patella: MR findings with surgical correlation in 14 patients. J Comput Assist Tomogr. 2001;25(6):957-62

6. Servien E, Fritsch B, Lustig S, Demey G, Debarge R, Lapra C, et al. In vivo positioning analysis of medial patellofemoral ligament reconstruction. Am J Sports Med. 2011;39(1):134-9.

7. Nomura E, Horiuchi Y, Kihara M. Medial patellofemoral ligament restraint in lateral patellar translation and reconstruction. Knee. 2000;7(2):121-7.

8. Ellera Gomes JL. Medial patellofemoral ligament reconstruction for recurrent dislocation of the patella: a preliminary report. Arthroscopy. 1992;8(3):335-40.

9. Avikainen VJ, Nikku RK, Seppanen-Lehmonen TK. Adductor magnus tenodesis for patellar dislocation. Technique and preliminary results. Clin Orthop Relat Res. 1993(297):12-6.

10. Burks RT, Luker MG. Medial patellofemoral ligament reconstruction. Tech Orthop. 1997;12:185-91.

11. Cohen M, editor. Transposição da inserção do vasto medial via artroscópica. São Paulo: Sarvier; 1996.

12. Muneta T, Sekiya I, Tsuchiya M, Shinomiya K. A technique for reconstruction of the medial patellofemoral ligament. Clin Orthop Relat Res. 1999(359):151-5.

13. Drez D, Jr., Edwards TB, Williams CS. Results of medial patellofemoral ligament reconstruction in the treatment of patellar dislocation. Arthroscopy. 2001;17(3):298-306.

14. Mikashima $Y$, Kimura M, Kobayashi $Y$, Asagumo H, Tomatsu T. Medial patellofemoral ligament reconstruction for recurrent patellar instability. Acta Orthop Belg. 2004;70(6):545-50.

15. Panagopoulos A, van Niekerk L, Triantafillopoulos IK. MPFL reconstruction for recurrent patella dislocation: a new surgical technique and review of the literature. Int J Sports Med. 2008;29(5):359-65.

16. Camanho GL, Bitar AC, Hernandez AJ, Olivi R. Medial patellofemoral ligament reconstruction: a novel technique using the patellar ligament. Arthroscopy. 2007;23(1):108 e1-4.

17. Davis DK, Fithian DC. Techniques of medial retinacular repair and reconstruction. Clin Orthop Relat Res. 2002;(402):38-52.

18. Amis AA, Firer P, Mountney J, Senavongse W, Thomas NP. Anatomy and biomechanics of the medial patellofemoral ligament. Knee. 2003;10(3):215-20.

19. Dhillon MS, Mohan P, Nagi ON. Does harvesting the medial third of the patellar tendon cause lateral shift of the patella after ACL reconstruction? Acta Orthop Belg. 2003;69(4):334-40. 
20. Ellera Gomes JL, Stigler Marczyk LR, Cesar de Cesar P, Jungblut CF. Medial patellofemoral ligament reconstruction with semitendinosus autograft for chronic patellar instability: a follow-up study. Arthroscopy. 2004;20(2):147-51.

21. Steensen RN, Dopirak RM, McDonald WG 3rd. The anatomy and isometry of the medial patellofemoral ligament: implications for reconstruction. Am J Sports Med. 2004;32(6):1509-13.

22. Steiner TM, Torga-Spak R, Teitge RA. Medial patellofemoral ligament reconstruction in patients with lateral patellar instability and trochlear dysplasia. Am J Sports Med. 2006;34(8):1254-61.

23. Feller JA, Amis AA, Andrish JT, Arendt EA, Erasmus PJ, Powers CM. Surgica biomechanics of the patellofemoral joint. Arthroscopy. 2007;23(5):542-53.

24. Sandmeier RH, Burks RT, Bachus KN, Billings A. The effect of reconstruction of the medial patellofemoral ligament on patellar tracking. Am J Sports Med. 2000;28(3):345-9.

25. Smirk $\mathrm{C}$, Morris $\mathrm{H}$. The anatomy and reconstruction of the medial patellofemoral ligament. Knee. 2003;10(3):221-7.

26. Mountney J, Senavongse W, Amis AA, Thomas NP. Tensile strength of the medial patellofemoral ligament before and after repair or reconstruction. Bone Joint Surg Br. 2005;87(1):36-40.

27. Ostermeier S, Stukenborg-Colsman C, Hurschler C, Wirth CJ. In vitro investigation of the effect of medial patellofemoral ligament reconstruction and medial tibial tuberosity transfer on lateral patellar stability. Arthroscopy. 2006;22(3):308-19

28. Bicos J, Carofino B, Andersen M, Schepsis AA, Fulkerson JP, Mazzocca A Patellofemoral forces after medial patellofemoral ligament reconstruction: a biomechanical analysis. J Knee Surg. 2006;19(4):317-26.

29. Amis AA. Current concepts on anatomy and biomechanics of patellar stability. Sports Med Arthrosc. 2007;15(2):48-56.

30. Beck P, Brown NA, Greis PE, Burks RT. Patellofemoral contact pressures and lateral patellar translation after medial patellofemoral ligament reconstruction. Am J Sports Med. 2007;35(9):1557-63.

31. Melegari TM, Parks BG, Matthews LS. Patellofemoral contact area and pressure after medial patellofemoral ligament reconstruction. Am J Sports Med 2008;36(4):747-52

32. Thaunat M, Erasmus PJ. Management of overtight medial patellofe- moral ligament reconstruction. Knee Surg Sports Traumatol Arthrosc. 2009;17(5):480-3

33. Tateishi T, Tsuchiya M, Motosugi N, Asahina S, Ikeda H, Cho S, et al. Graft length change and radiographic assessment of femoral drill hole position for medial patellofemoral ligament reconstruction. Knee Surg Sports Traumatol Arthrosc. 2011;19(3):400-7.

34. Ostermeier S, Holst M, Bohnsack M, Hurschler C, Stukenborg-Colsman C, Wirth CJ. In vitro measurement of patellar kinematics following reconstruction of the medial patellofemoral ligament. Knee Surg Sports Traumatol Arthrosc. 2007;15(3):276-85.

35. Abdel-Aziz YI, Karara HM, editors. Direct linear transformation from comparator coordinates into object space coordinates in close-range photogrammetry. Falls Church, VA: American Society of Photogrammetry; 1971.

36. Neter J, Kutner MH, Nachtsheim CJ, Wasserman W, editors. Applied linear statistical models. Chicago: Irwin; 1996.

37. Ahmad CS, Stein BE, Matuz D, Henry JH. Immediate surgical repair of the medial patellar stabilizers for acute patellar dislocation. A review of eight cases. Am J Sports Med. 2000;28(6):804-10.

38. Watanabe T, Muneta T, Ikeda H, Tateishi T, Sekiya I. Visual analog scale assessment after medial patellofemoral ligament reconstruction: with or without tibial tubercle transfer. J Orthop Sci. 2008;13(1):32-8.

39. Elias JJ, Cosgarea AJ. Technical errors during medial patellofemoral ligament reconstruction could overload medial patellofemoral cartilage: a computational analysis. Am J Sports Med. 2006;34(9):1478-85.

40. Ostermeier S, Holst M, Bohnsack M, Hurschler C, Stukenborg-Colsman C, Wirth CJ. Dynamic measurement of patellofemoral contact pressure following reconstruction of the medial patellofemoral ligament: an in vitro study. Clin Biomech (Bristol, Avon). 2007;22(3):327-35

41. Senavongse $W$, Amis AA. The effects of articular, retinacular, or muscular deficiencies on patellofemoral joint stability. J Bone Joint Surg $\mathrm{Br}$. 2005;87(4):577-82.

42. Durselen L, Claes L, Kiefer $H$. The influence of muscle forces and external loads on cruciate ligament strain. Am J Sports Med. 1995;23(1):129-36. 